\title{
EFICIÊNCIA AGRONÔMICA DO CONSÓRCIO ALFACE-RÚCULA FERTILIZADO COM FLOR-DE-SEDA ${ }^{1}$
}

\author{
ANTONIO EWERTON DA SILVA ALMEIDA ${ }^{2}$, FRANCISCO BEZERRA NETO ${ }^{2}$, LUCAS RAMOS COSTA ${ }^{2}$, \\ MAIELE LEANDRO DA SILVA ${ }^{2}$, JAILMA SUERDA SILVA DE LIMA ${ }^{2}$, AURÉLIO PAES BARROS JÚNIOR ${ }^{2}$
}

\begin{abstract}
Resumo - O presente trabalho teve como objetivo avaliar o desempenho agronômico do consórcio de alface e rúcula fertilizado com diferentes quantidades de biomassa de flor-de-seda incorporadas ao solo. $\mathrm{O}$ experimento foi conduzido no período de setembro a novembro de 2011, na área de pesquisa da Fazenda Experimental Rafael Fernandes da Universidade Federal Rural do Semi-Árido, Mossoró-RN. O delineamento experimental utilizado foi em blocos ao acaso com cinco tratamentos e quatro repetições. Os tratamentos consistiram das seguintes quantidades de biomassa de flor-de-seda incorporadas ao solo $\left(5,15,25,35\right.$ e $45 \mathrm{t} \mathrm{ha}^{-1}$ em base seca). As características avaliadas nas hortaliças foram: altura e diâmetro de plantas (alface), número de folhas por planta, produtividade (alface), rendimento de massa verde (rúcula) e massa seca da parte aérea. A eficiência do cultivo consorciado foi determinada pelo escore da variável canônica. A otimização do desempenho agronômico da alface consorciada com rúcula foi viabilizada com a incorporação de aproximadamente $37 \mathrm{t} \mathrm{ha}^{-1}$ de flor-deseda ao solo. O uso de flor-de-seda como adubo verde é viável agronomicamente no cultivo associado de alface e rúcula, além de contribuir para um melhor aproveitamento dos recursos ambientais.
\end{abstract}

Palavras-chave: Adubação verde. Consorciação de culturas. Calotropis procera. Eruca sativa. Lactuca sativa.

\section{AGRONOMIC EFFICIENCY OF THE INTERCROPPING LETTUCE-ARUGULA FERTILIZED WITH ROOSTERTREE}

\begin{abstract}
The present work aimed to evaluate the agronomic performance of lettuce-arugula intercropping fertilized with different amounts of roostertree biomass incorporated into the ground. The experiment was conducted during the period of September to November of 2011, in the research area of the Experimental Farm Rafael Fernandes, Universidade Federal Rural do Semi-Árido, Mossoró-RN. The experimental design used was randomized blocks with five treatments and four replications. The treatments consisted of the following biomass amounts of roostertree incorporated into the soil $\left(5,15,25,35\right.$, and $45 \mathrm{t} \mathrm{ha}^{-1}$ on a dry basis). The characteristics evaluated in the vegetables were: height and diameter of plants (lettuce), number of leaves per plant, productivity (lettuce), yield of green mass (arugula) and dry mass of shoots. The efficiency of intercropping system was determined through the score of the canonical variable. The optimization of the agronomic performance of the lettuce intercropped with arugula was made possible with the incorporation of about $37 \mathrm{t} \mathrm{ha}^{-1}$ of roostertree into the ground. The use of roostertree as green manure is agronomically viable in the intercropping of lettuce and arugula besides contributing to a better use of environmental resources.
\end{abstract}

Keywords: Green manure. Intercropping. Calotropis procera. Eruca sativa. Lactuca sativa.

\footnotetext{
*Autor para correspondência

${ }^{1}$ Recebido para publicação em .11/07/2014; aceito em 24/04/2015.

Parte da Dissertação de Mestrado do primeiro autor apresentada na Universidade Federal Rural do Semi-Árido (UFERSA).

${ }^{2}$ Departamento de Ciências Ambientais/UFERSA, Mossoró-RN, Brasil, 59.625-900; ewerton-almeida@hotmail.com, bezerra@ufersa.edu.br, aurelio.barros@ufersa.edu.br
} 


\section{INTRODUÇ̃̃̃O}

A consorciação entre hortaliças folhosas está crescendo no Nordeste brasileiro, principalmente em moldes agroecológicos, apresentando diversas vantagens nos aspectos produtivo, nutricional, econômico e ambiental. Com esta prática, busca-se maior produção por área pela combinação de plantas que irão utilizar espaço, nutrientes e luz solar, além dos benefícios que uma planta traz para a outra no controle de plantas concorrentes, pragas e doenças (PIVETTA, et al., 2007; SILVA et al., 2011). Entre as espécies olerícolas que se pode combinar com vantagens agroeconômicas e ambientais estão a alface e rúcula (COSTA et al., 2007; OLIVEIRA et al., 2010). Elas têm elevado valor nutricional, são bastante usadas na alimentação humana e contribuem primariamente com vitaminas e sais minerais.

No entanto, o grande desafio no cultivo consorciado dessas culturas está na forma como elas devem ser associadas, principalmente no que tange ao manejo do sistema, tendo como meta a maximização do uso da terra e dos recursos ambientais disponíveis e o atendimento aos interesses dos produtores.

Uma das práticas que vem sendo utilizada com bastante sucesso em cultivos consorciados em hortaliças é a adubação verde com espécies espontâneas existentes no bioma Caatinga. Essas espécies apresentam inúmeras vantagens diante das plantas exóticas, como menor custo de obtenção, serem adaptadas às condições ambientais e produzirem elevadas quantidades de biomassa (ANDRADE FILHO, 2012; LINHARES et al., 2009a; LINHARES et al., 2009b; GÓES et al., 2011).

As espécies espontâneas da Caatinga utilizadas como adubo verde em algumas hortaliças folhosas em cultivo solteiro têm demonstrado resultados promissores como, por exemplo, a jitirana (Merremia aegyptia L.) nas culturas da alface (BEZERRA NETO et al., 2011; GÓES et al., 2011), na rúcula (LINHARES et al., 2009a) e no coentro (LINHARES et al., 2012). Esta última também tem demonstrado bons resultados quando adubada com mata-pasto (Senna uniflora L.) (LINHARES et al., 2010).

Outra espécie espontânea também bastante comum no Nordeste brasileiro é a Calotropis procera Ait., pertencente à família da Apocynaceae, popularmente conhecida como flor-de-seda, possuindo diversos sinônimos de acordo com as regiões do Brasil. Esta planta além de ser muito prolífera tem uma capacidade de oferta de fitomassa o ano inteiro, até mesmo em épocas de seca, conferindo uma posição de destaque em relação a diversas espécies nativas e naturalizadas da Caatinga. É válido ressaltar que seu tecido dispõe de altas concentrações de $\mathrm{N}, \mathrm{P}$ e $\mathrm{K}$, podendo alcançar valores em torno de 22,7, 10,0 e $28,9 \mathrm{~g} \mathrm{~kg}^{-1}$, respectivamente (SILVA et al., 2013).

Estudos envolvendo o uso da flor-de-seda como adubo verde em hortaliças ainda estão em fase inicial. Entretanto, esta espécie tem demonstrado resultados promissores nas culturas de rúcula (LINHARES et al., 2009b) e de alface em cultivo solteiro (LIMA, 2012).

Com o intuito de fornecer subsídios às pesquisas de consórcios entre hortaliças fertilizadas com espécies espontâneas da Caatinga, objetivou-se com este trabalho avaliar o desempenho agronômico do cultivo consorciado entre alface e rúcula sob condições de adubação verde com de flor-de-seda incorporada ao solo.

\section{MATERIAL E MÉTODOS}

O experimento foi conduzido na área experimental da Fazenda Rafael Fernandes, da Universidade Federal Rural do Semi-Árido, Mossoró (RN), localizada no distrito de Alagoinha, distante $20 \mathrm{~km}$ da sede do município de Mossoró (5 ${ }^{\circ} 11^{\prime} \mathrm{S} ; 37^{\circ} 20^{\prime}$ $\mathrm{W} ; 18 \mathrm{~m}$ de altitude), no período de setembro a novembro de 2011. O clima da região, pela classificação de Köppen, é BsWh, ou seja, seco, muito quente e com estação chuvosa no verão, atingindo temperatura média máxima entre 32,1 e $34,50{ }^{\circ} \mathrm{C}$ e média mínima entre 21,3 e $23,70{ }^{\circ} \mathrm{C}$, sendo junho e julho os meses mais frios e a precipitação média anual em torno de $700 \mathrm{~mm}$.

O delineamento experimental utilizado foi em blocos ao acaso com cinco tratamentos e quatro repetições. Os tratamentos consistiram das seguintes quantidades de biomassa de flor-de-seda incorporadas ao solo: $5,15,25,35$ e $45 \mathrm{t} \mathrm{ha}^{-1}$ em base seca. Cada parcela experimental teve área total de $2,88 \mathrm{~m}^{2}$, com área útil de $1,60 \mathrm{~m}^{2}$. O cultivo consorciado foi estabelecido em faixas de quatro fileiras alternadas de cada cultura, ladeadas por duas fileiras (bordaduras) de rúcula por um lado e de duas de alface pelo outro lado. O espaçamento da alface foi de $0,20 \mathrm{~m} \times 0,10 \mathrm{~m}$, com uma planta por cova, e da rúcula de $0,20 \mathrm{~m} \times 0,05 \mathrm{~m}$, contendo uma planta por cova, resultando em uma população de 250.000 plantas ha ${ }^{-1}$ de alface e 1.000 .000 plantas $h^{-1}$ de rúcula. A cultivar de alface plantada foi a "Tainá" e a da rúcula a "Cultivada".

O solo da área experimental foi classificado como Latossolo Vermelho-Amarelo Eutrófico (EMBRAPA, 2006). Antes da instalação do experimento em campo foram coletadas 20 amostras simples do solo a profundidade de $0-20 \mathrm{~cm}$ e posteriormente homogeneizadas para se obter uma amostra composta, a qual foi enviada para análise ao Laboratório de Analise de Solo, Água e Planta do Departamento de Ciências Ambientais da UFERSA, cujos resultados foram: $\mathrm{pH}$ (água) $=6,45$; M.O. $=6,45 \mathrm{~g}$ $\mathrm{kg}^{-1} ; \mathrm{N}=0,45 \mathrm{~g} \mathrm{~kg}^{-1} ; \mathrm{P}=3,4 \mathrm{mg} \mathrm{dm}^{-3} ;(\mathrm{H}+\mathrm{Al})=0,00$ $\mathrm{cmol}_{\mathrm{c}} \mathrm{dm}^{-3} ; \mathrm{K}^{+}=0,18 \mathrm{cmol}_{\mathrm{c}} \mathrm{dm}^{-3} ; \mathrm{Ca}^{2+}=1,85 \mathrm{cmol}_{\mathrm{c}}$ $\mathrm{dm}^{-3} ; \mathrm{Mg}^{2+}=0,37 \mathrm{cmol}_{\mathrm{c}} \mathrm{dm}^{-3} ; \mathrm{Na}^{+}=0,11 \mathrm{cmol}_{\mathrm{c}} \mathrm{dm}^{-3}$; $\mathrm{SB}=2,48 \mathrm{cmol}_{\mathrm{c}} \mathrm{dm}^{-3}$; CTCpH7 $=2,48 \mathrm{cmol}_{\mathrm{c}} \mathrm{dm}^{-3}$; $\mathrm{V} \%=100$; e $\mathrm{CE}=0,14 \mathrm{dS} \mathrm{m}^{-1}$. 
A flor-de-seda utilizada como adubo verde foi coletada em diversas localidades da zona rural do município de Mossoró ( $\mathrm{RN}$ ) antes do início de sua floração. Após a colheita as plantas foram trituradas, obtendo-se partículas fragmentadas com granulometria em torno de 2,0 a 3,0 cm, as quais foram desidratadas sob temperatura ambiente até atingir o teor de umidade de $10 \%$ e depois submetidas a análises em laboratório, cuja composição química obtida foi: $\mathrm{N}=$ $29,58 \mathrm{~g} \mathrm{~kg}^{-1} ; \mathrm{P}=4,08 \mathrm{~g} \mathrm{~kg}^{-1}$; e $\mathrm{K}=50,09 \mathrm{~g} \mathrm{~kg}^{-1}$ e relação C:N de 20:1.

O preparo do solo da área experimental consistiu de uma gradagem seguida pelo levantamento dos canteiros. A incorporação da flor-de-seda foi realizada aos dez dias antes do transplante da alface e o semeio da rúcula. A irrigação foi realizada diariamente por microaspersão em dois turnos de rega (manhã e tarde), proporcionando uma lâmina de 8 $\mathrm{mm} \mathrm{dia}{ }^{-1}$. E o controle de plantas concorrentes foi realizado por capinas realizadas manualmente.

A semeadura da alface foi realizada em 6 setembro de 2011 em bandejas de poliestireno expandido com 128 células, colocando-se duas a três sementes por célula. $\mathrm{O}$ desbaste foi realizado 15 dias após o semeio, deixando-se uma plântula por célula. As plântulas da alface foram condicionadas em ambiente aberto e coberto com tela de sombreamento preta a $40 \%$. O transplante da alface e o semeio da rúcula foram realizados simultaneamente em 26 de setembro de 2011. As sementes de rúculas foram colocadas a uma profundidade de $2 \mathrm{~cm}$.

A colheita da alface foi efetuada aos 29 dias após o transplante, quando as plantas atingiram o máximo crescimento vegetativo. E a rúcula colhida aos 35 dias após a semeadura, cortando-se as plantas rente ao solo na base do caule.

$\mathrm{Na}$ cultura da alface, avaliações foram realizadas em amostras de 5 plantas e na rúcula de 20 plantas colhidas aleatoriamente dentro da área útil de cada parcela, onde no Laboratório de Pós-Colheita da UFERSA foram determinadas as seguintes características: altura e diâmetro de plantas (alface); número de folhas por planta; produtividade da alface; rendimento de massa verde da rúcula; e massa seca da parte aérea.

A altura de plantas foi determinada através de medição a partir do nível do solo até a extremidade da folha mais alta com o auxilio de uma régua graduada em centímetros. O diâmetro de plantas foi efetuado medindo-se a distância entre as margens opostas do disco foliar. O número de folhas foi determinado na mesma amostra pela contagem direta do número de folhas com comprimentos superiores a $5 \mathrm{~cm}$ na alface e $3 \mathrm{~cm}$ na rúcula. A produtividade da alface $\mathrm{e}$ o rendimento de massa verde da rúcula foram determinados através da massa fresca da parte aérea de todas as plantas da área útil e expressos em $\mathrm{t} \mathrm{ha}^{-1}$. A massa seca da parte aérea foi tomada da mesma amostra, na qual se determinou a altura de plantas, em estufa com circulação forçada de ar à temperatura de $65{ }^{\circ} \mathrm{C}$ até atingir peso constante, expressa em tha 1 .

A eficiência do sistema consorciado foi determinada pelo escore da variável canônica, obtida através da análise bivariada de variância da produtividade da alface e do rendimento de massa verde da rúcula.

As análises de variância foram realizadas nas características avaliadas nas hortaliças e na variável canônica. Análise de regressão também foi realizada para avaliar o comportamento de cada característica em função das quantidades de biomassa utilizadas, através de um procedimento de ajustamento de curvas de resposta.

\section{RESULTADOS E DISCUSSÃO}

\section{Cultura da alface}

Pelos resultados da análise de regressão (Tabela 1 e Figura 1), pode-se observar que a altura e diâmetro de plantas, número de folhas por planta, produtividade e massa seca da parte aérea da alface aumentaram com as crescentes quantidades de biomassa de flor-de-seda incorporadas ao solo, como adubo verde (em um modelo polinomial), até as quantidades de 37,$83 ; 35,88 ; 40,40 ; 36,69$ e $42,31 \mathrm{t}$ $\mathrm{ha}^{-1}$, respectivamente, onde foram registrados os valores máximos dessas variáveis, quais sejam, $15,20 \mathrm{~cm}, 25,66 \mathrm{~cm}, 12,6$ folhas, 15,78 e 1,45 $\mathrm{t} \mathrm{ha}^{-1}$, decrescendo, em seguida, até a maior quantidade de adubo incorporada ao solo (Figuras 1A a 1D). As respostas ascendentes e a otimização dessas variáveis podem ser atribuídas a Lei do máximo, onde o excesso de um nutriente no solo pode provocar efeito tóxico e/ou diminuir a eficácia de outros, acarretando na redução da produção. Outro fator que pode estar relacionado a adequada sincronia entre a decomposição e mineralização da flor-de-seda adicionada é a época de maior exigência nutricional da cultura (FONTANÉTTI et al., 2006). 
Tabela 1. Valores de "F" para altura de plantas (AP), diâmetro de plantas (DP), número de folhas por planta (NFP), produtividade (PROD) e massa seca da parte aérea (MSPA) da alface consorciada com rúcula em função de quantidades de biomassa de flor-de-seda incorporadas ao solo.

\begin{tabular}{lcccccc}
\hline \multicolumn{1}{c}{ Fontes de variação } & GL & AP & DP & NFP & PROD & MSPA \\
\hline Blocos & 3 & $7,32^{* *}$ & $6,81^{* *}$ & $0,04^{\text {ns }}$ & $0,31^{\text {ns }}$ & $0,95^{\text {ns }}$ \\
Quantidades de biomassa de flor-de-seda & $(4)$ & $18,21^{* *}$ & $18,35^{* *}$ & $8,25^{* *}$ & $20,12^{* *}$ & $6,99^{* *}$ \\
Regressão polinomial & 2 & $70,66^{*}$ & $68,04^{*}$ & $121,18^{* *}$ & $747,99^{* *}$ & $91,88^{* *}$ \\
\hline CV & & 7,82 & 7,84 & 11,29 & 18,5 & 18,79 \\
Média geral & & 13,39 & 22,23 & 10,97 & 10,75 & 1,2 \\
\hline
\end{tabular}

$* *=\mathrm{P}<0,01 ; *=\mathrm{P}<0,05 ;{ }^{\mathrm{ns}}=\mathrm{P}>0,05$.
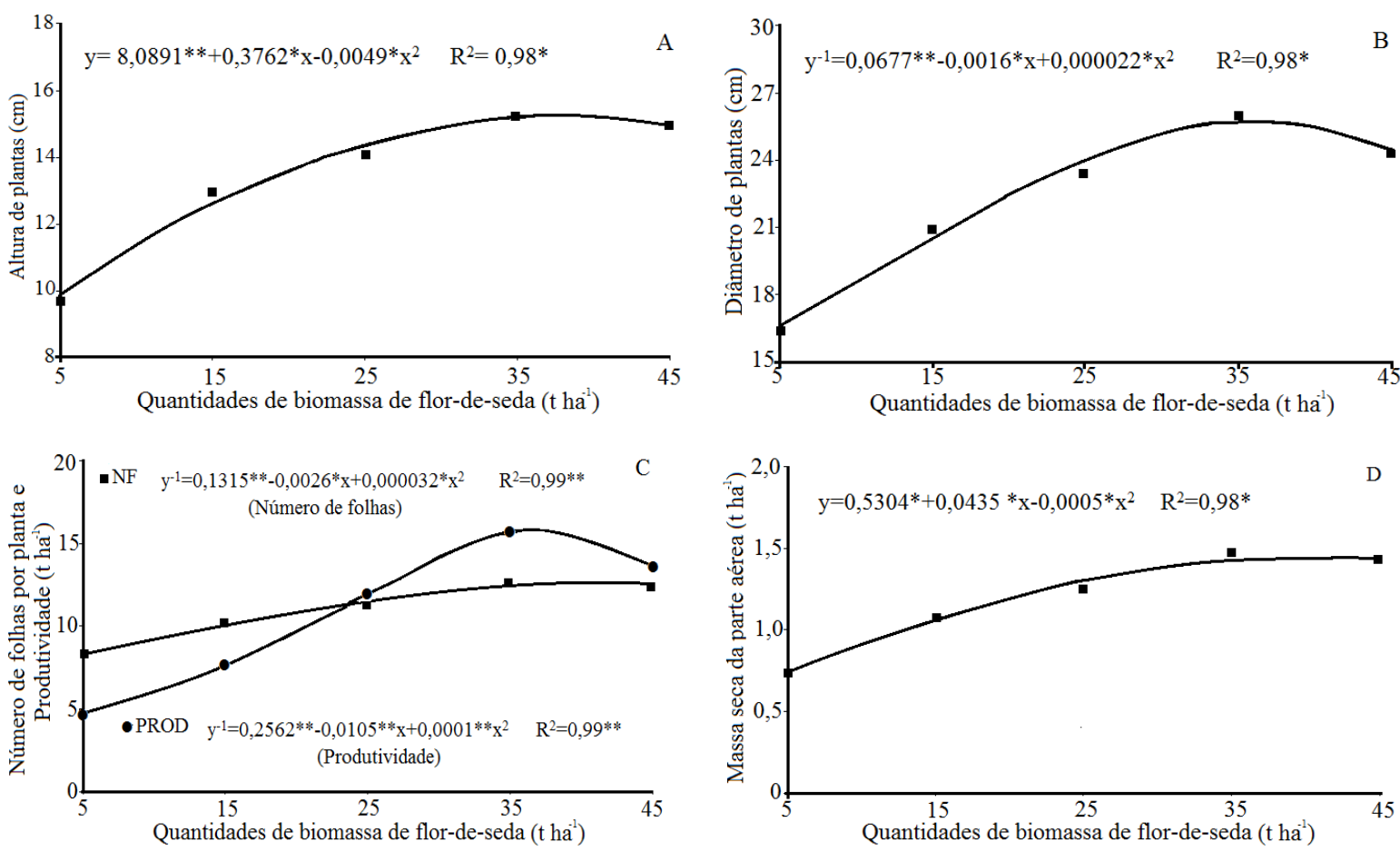

Figura 1. Altura e diâmetro de plantas, número de folhas por planta, produtividade e massa seca da parte aérea da alface consorciada com rúcula em função das quantidades de biomassa de flor-de-seda incorporadas ao solo.

A flor-de-seda é um adubo verde que possui uma relação $\mathrm{C} / \mathrm{N}$ entre 20 e $30: 1$, o que contribuiu para uma decomposição mais rápida e liberação dos nutrientes, evidenciada pela incorporação desse adubo no tempo de 10 dias antes do transplantio da alface nas características avaliadas. Sabe-se, no entanto, que a taxa de decomposição de resíduos orgânicos está ligada à relação carbono:nitrogênio $(\mathrm{C}: \mathrm{N})$ do material sob esse processo, que no caso da flor-deseda é de 20:1, e que a mineralização do $N$ também é muito influenciada por esta relação $\mathrm{C}: \mathrm{N}$ do material em decomposição (VALE et al., 2004).

\section{Cultura da rúcula}

A altura de plantas e o rendimento de massa verde da rúcula aumentaram com as quantidades de biomassa de flor-de-seda em um modelo polinomial (Tabela 2 e Figura 2) até as quantidades de 35,51 e $37,96 \mathrm{tha}^{-1}$, respectivamente, onde foram registrados os valores máximos dessas variáveis $(15,16 \mathrm{~cm} \mathrm{e}$ 4,30 $\mathrm{t} \mathrm{ha}^{-1}$ ), decrescendo, em seguida, até a maior quantidade de adubo incorporada ao solo (Figuras 2A e 2B).

Também foi observado um aumento da ordem de 1,1 folhas por planta e de $0,22 \mathrm{t} \mathrm{ha}^{-1}$ nos valores médios do número de folhas por planta e massa seca da parte aérea de rúcula entre a menor e a maior quantidade de biomassa da flor-de-seda adicionada ao solo, com valores máximos de 6,4 folhas por planta e $0,94 \mathrm{t} \mathrm{ha}^{-1}$ registrados na maior quantidade de flor-de-seda (45,00 t ha ${ }^{-1}$ ) (Figuras 2A e 2B). Uma possível explicação para esse desempenho da rúcula está no fato da flor-de-seda apresentar valores altos 
dos teores de $\mathrm{N}$ e $\mathrm{K} \quad\left(\mathrm{N}=29,58 \mathrm{~g} \mathrm{~kg}^{-1}\right.$ e $\mathrm{K}=50,09 \mathrm{~g} \mathrm{~kg}^{-1}$ ) na sua composição. Além disso, a rúcula tem uma alta demanda por $\mathrm{N}$ e $\mathrm{K}$ e fornecidos esses nutrientes nessa fase também. Outro fator im- portante da flor-de-seda foi a sua relação $\mathrm{C}: \mathrm{N}$ de 20:1, a qual facilitou a sua rápida decomposição e liberação dos nutrientes.

Tabela 2. Valores de "F" para altura de plantas (AP), número de folhas por planta (NFP), rendimento de massa verde (RMV), massa seca da parte aérea (MSPA) de rúcula consorciada com alface e escore da variável canônica $Z$ do consórcio alface $\mathrm{x}$ rúcula em função de quantidades de biomassa de flor-de-seda incorporadas ao solo.

\begin{tabular}{lcccccr}
\hline \multicolumn{1}{c}{ Fontes de variação } & GL & AP & NFP & RMV & MSPA & Z \\
\hline Blocos & 3 & $0,2^{\text {ns }}$ & $0,57^{\text {ns }}$ & $0,79^{\text {ns }}$ & $1,44^{\text {ns }}$ & $0,89^{\text {ns }}$ \\
Quantidades de biomassa de flor-de-seda & $(4)$ & $5,5^{* *}$ & $3,11^{\text {ns }}$ & $8,49^{* *}$ & $3,62^{*}$ & $35,59^{* *}$ \\
Regressão polinomial & 2 & $38,90^{*}$ & $52,15^{* *}$ & $205,79^{* *}$ & $55,59^{* *}$ & $252,98^{* *}$ \\
\hline CV & & 8,91 & 9,7 & 15,09 & 11,07 & 10,76 \\
Média geral & & 13,49 & 6,15 & 3,46 & 0,84 & 2,68 \\
\hline
\end{tabular}

$* *=\mathrm{P}<0,01 ; *=\mathrm{P}<0,05 ;{ }^{\mathrm{ns}}=\mathrm{P}>0,05$
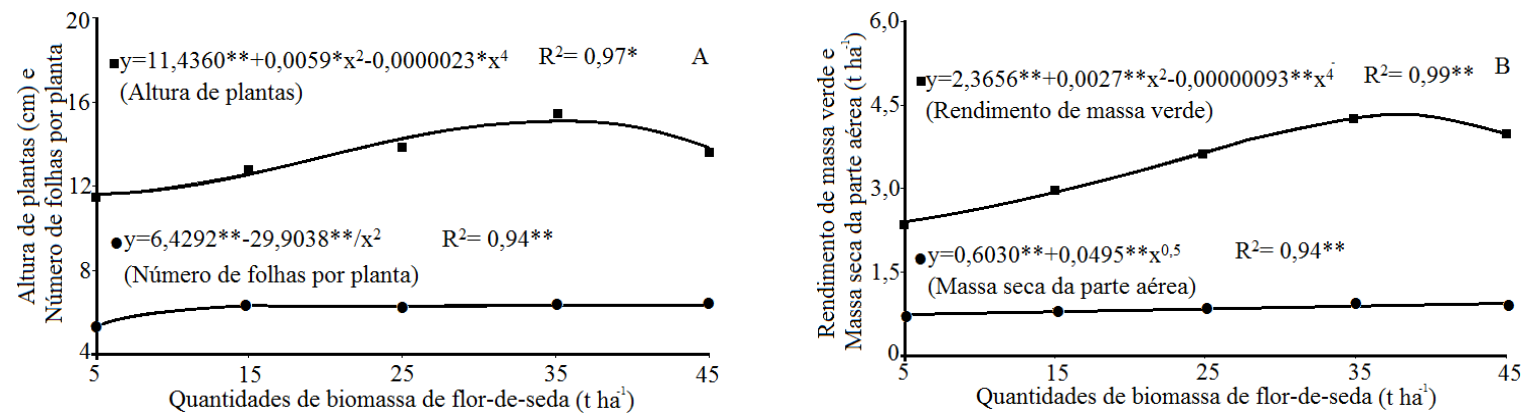

Figura 2. Altura de plantas, número de folhas por planta, rendimento de massa verde e massa seca da parte aérea da rúcula consorciada com alface em função de quantidades de biomassa de flor-de-seda incorporadas ao solo.

Os estudos envolvendo o uso da flor-de-seda como adubo verde em hortaliças folhosas ainda estão em fase inicial. Entretanto, esta espécie tem demonstrado resultados promissores em termos de desempenho produtivo nas culturas da rúcula (LINHARES et al., 2009b) e da alface em cultivo solteiro (LIMA, 2012).

\section{Eficiência do consórcio alface $\mathbf{x}$ rúcula}

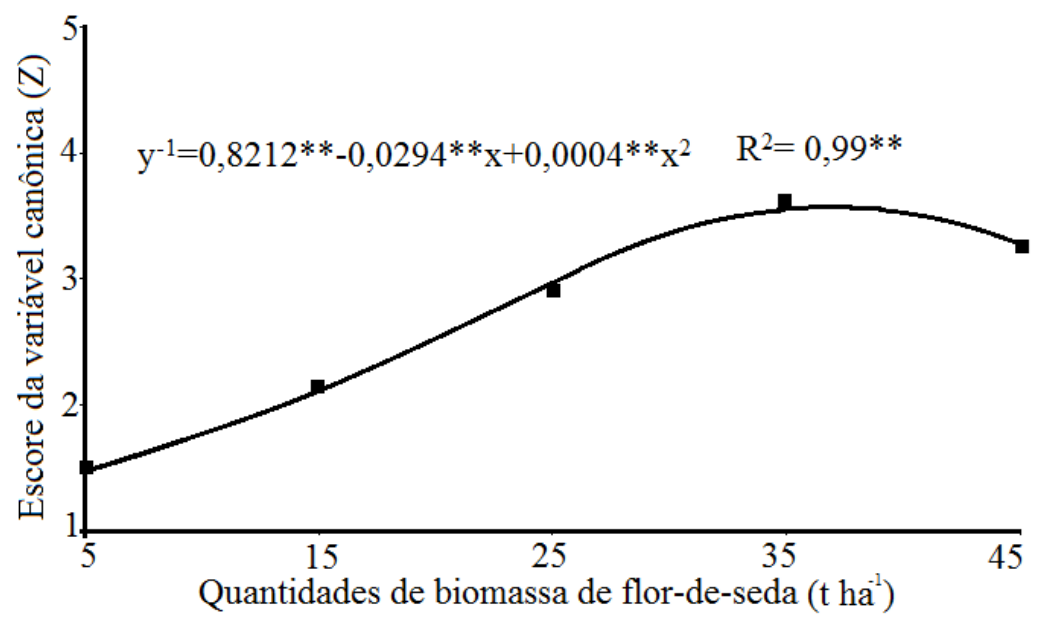

Figura 3. Escore da variável canônica do consórcio alface x rúcula em função de quantidades de biomassa de flor-de-seda incorporadas ao solo.

Revista Caatinga, Mossoró, v. 28, n. 3, p. 79 - 85, jul. - set., 2015 
Esse resultado se deve ao fato do consórcio ter respondido muito bem à adubação verde com flor -de-seda devido ao melhor aproveitamento dos recursos ambientais pelas plantas de alface e rúcula, proporcionadas pelas quantidades de flor-de-seda testadas, cujo aproveitamento foi traduzido em eficiência agronômica. Sabe-se que a adubação verde melhora a fertilidade, aumenta o teor de matéria orgânica, diminui os índices de erosão, aumenta a retenção de água no solo e a atividade da microbiota do solo aumentando a disponibilidade de nutrientes e reduzindo a quantidade de plantas invasoras (GRAHAM; HAYNES, 2006).

\section{CONCLUSÕES}

A otimização do desempenho agronômico da alface consorciada com rúcula foi viabilizada com a incorporação de cerca de $36,9 \mathrm{t} \mathrm{ha}^{-1}$ de flor-de-seda ao solo.

O uso de flor-de-seda como adubo verde é viável agronomicamente no cultivo consorciado de alface e rúcula, além de contribuir para um melhor aproveitamento dos recursos ambientais.

\section{REFERÊNCIAS}

ANDRADE FILHO, F. C. Bicultivo de folhosas consorciadas com beterraba em função de adubação com flor-de-seda e densidades populacionais. 2012. 94 p. Tese (Doutorado em Fitotecnia: Área de concentração em Práticas Culturais) - Universidade Federal Rural do Semi-árido, Mossoró, 2012.

BEZERRA NETO, F. et al. Desempenho agronômico da alface em diferentes quantidades e tempos de decomposição de jitirana verde. Revista Brasileira de Ciências Agrárias, Recife, v. 6, n. 2, p. 236-242, jun. 2011.

COSTA, C. C. et al. Viabilidade agronômica do consórcio de alface e rúcula, em duas épocas de cultivo. Horticultura Brasileira, Brasília, v. 25, n. 1, p. 34 40, 2007.

EMBRAPA - Empresa Brasileira de Pesquisa Agropecuária. Centro nacional de Pesquisas de Solos. Sistema Brasileiro de Classificação de Solos. Rio de janeiro: EMBRAPA. 2006. 306 p.

FONTANÉTTI, A. et al. Adubação verde na produção orgânica de alface americana e repolho. Horticultura Brasileira, Brasília, v. 24, n. 2, p. 146-150, 2006.

GÓES, S. B. et al. Productive performance of lettuce at different amounts and times of decomposition of dry scarlet starglory. Revista Ciência Agronômica, Fortaleza, v. 42, n. 4, p. 1036-1042, 2011.

GRAHAM, M. H.; HAYNES, R. J. Organic matter status and the size, activity and metabolic diversity of the soil microbial community in the row and interrow of sugar cane under burning a trash retention. Soil Biology \& Biochemistry, Oxford, v. 38, n. 1, p. 21- 31, 2006.

LIMA, E. F. Produtividade e rentabilidade da alface adubada com flor de seda. 2012. 66 p. Dissertação (Mestrado em Produção vegetal: Área de Concentração em Produção Vegetal no Semiárido) Universidade Federal Rural do Pernambuco, Serra Talhada, 2012.

LINHARES, P. C. F. et al. Velocidade de decomposição da flor-de-seda no desempenho agronômico da rúcula cv. Cultivada. Revista Verde Agroecologia e Desenvolvimento Sustentável, Mossoró, v. 4, n. 2, p. 46-50, 2009a.

LINHARES, P. C. F. et al. Influência da jitirana em cobertura como adubação verde sobre o desenvolvimento agronômico da alface. Revista Caatinga, Mossoró, v. 22, n. 4, p. 65-69, 2009 b.

LINHARES, P. C. F. et al. Adubação verde em diferentes proporções de jitirana com mata-pasto incorporado ao solo na produtividade de coentro. Revista Verde Agroecologia e Desenvolvimento Sustentável, Mossoró, v. 5, n. 1, p. 91-95, 2010.

LINHARES, P. C. F. et al. Quantidades e tempos de decomposição da jitirana no desempenho agronômico do coentro. Ciência Rural, Santa Maria, v. 42, n. 2, p. 243-248, 2012.

OLIVEIRA, E. Q. et al. Produtividade de alface e rúcula, em sistema consorciado, sob adubação orgânica e mineral. Horticultura Brasileira, Brasília, v. 28 , n. 1 , p. $36-40,2010$

PIVETTA, L. A. et al. Avaliação do cultivo consorciado de rúcula com alface, em sistema orgânico e biodinâmico na região oeste do Paraná. Cadernos de Agroecologia, Guarapari, v. 2, n. 2, p. 1682-1685, 2007.

SILVA, H. D. et al. Viabilidade agronômica de consórcios entre alface e rúcula no sistema orgânico de produção. Cadernos de Agroecologia, Fortaleza, v. 6, n.2, p. 2-5, 2011.

SILVA, M. L. et al. Produção de cenoura fertilizada com flor-de-seda (Calotropis procera (Ait.) R.Br.). Revista Ciência Agronômica, Fortaleza, v. 44, n. 4, p. 732-740, 2013. 
VALE, F. R.; GUILHERME, L. R. G.; GUEDES, G.

A. A. Fertilidade do solo: dinâmica e disponibilidade dos nutrientes de plantas. Lavras: Editora UFLA, 2004. $171 \mathrm{p}$. 